\title{
Innovative Practice and Promotion Countermeasures of Micro-major in Chinese Universities
}

\author{
Huaide Wen, Jun Dai \\ Qianjiang College, Hangzhou Normal University, Hangzhou, Zhejiang, China \\ *Corresponding Author.
}

\begin{abstract}
Traditional talent training at universities can no longer meet the changing needs of talents brought about by rapid social and economic development. A more flexible, faster, and lower-cost talent training method of micro-majors is gradually introduced into the practice of talent training at universities. Micro-major has become an important means to make up for the lagging of majors setting at universities and a supplement to increase the supply of talents in emerging industries. The micro-major curriculum system simplifies theoretical teaching and emphasizes applied practice, which is conducive to better social training. Online and offline teaching methods are generally adopted, and the school-enterprise cooperation model is introduced, which alleviate the shortage of teachers for talent training in emerging industries to a certain extent. However, the development of micro-majors also needs to improve the actual effect of practical teaching, strengthen the construction of dual-qualified and dual-capable teacher teams, and take into account the relationship between micro-majors and general majors.
\end{abstract}

Keywords: Micro-major, major setting, MOOC, online and offline teaching.

\section{Introduction}

With the advancement of science and technology and rapid changes in the division of labor in society, new industries and occupations continue to emerge. The establishment of majors in Chinese colleges and universities is lagging and the training cycle is long, which can no longer meet the needs of social and economic development. A more flexible, faster, and lower-cost talent training method-"micro-majors" is gradually introduced into the practice of talent training. The first to implement micro-majors was MOOC platforms or Internet companies, and then gradually introduced to the training of talents at universities. Micro-majors have also shifted from relying on MOOC platform courses to more self-developed MOOCs, SPOCs, offline courses, and other courses, adopting online and offline integration and even only offline methods to carry out micro-major teaching.

The basic characteristics of micro-majors generally include (1) Flexible customized courses for occupations. Micro-majors can flexibly set training goals and courses by refining the core skills of a certain position group; (2) The curriculum system is streamlined and the structure is complete (small and refined). The curriculum is generally no more than 10 courses, consisting of basic courses, professional courses, practical training, and internships; (3) Concentrated time for rapid training. The micro-major study time is mostly six months to one year, generally not more than two years; (4) The teaching cost is relatively low. Due to the streamlined curriculum system, short training period, relying on the Internet platform, the cost of teaching staff and laboratories is relatively low; (5) The scope of benefits is wide. Enterprise-led micro-majors recruit students from the whole society, while college-led micro-majors generally recruit students from the university; (6) A supplement to traditional education. Micro-majors generally exist as adult continuing education, or as a supplement beyond majors at universities.

\section{The Emergence and Development of Micro-Majors}

ISSN: 0010-8189

(C) CONVERTER 2020

www.converter-magazine.info 
With the rapid accumulation of MOOC resources and the effective promotion of MOOC learning methods, various MOOC platforms have been exploring profit models, and a career- and ability-oriented micro-major model has emerged [1-2]. Micro-majors have different expressions on different MOOC platforms, such as Specializations, Programs, Degrees, etc. In 2012, MIT and Harvard University jointly created the MOOC platform edX, released the $\mathrm{X}$-series certification project a year later, and set up two micro-majors of Logistics Management and Introduction to Computer Skills. Later, Coursera launched Free Online Courses From Top Universities, which is called a special course. In 2014, Udacity cooperated with AT\&T to propose the Nanodegree program, which has provided micro-majors in 28 emerging fields such as artificial intelligence, machine learning, and driverless vehicles [3-4]. In China, Netease Cloud Classroom released the first micro-major of "iBA: Economic General Studies" in 2013, which includes eight compulsory courses. Micro-major is mainly composed of four parts: course study, practice inspection, certificate awarding, and employment connection [5]. Curriculum resources mainly come from first-class domestic universities.

The micro-major of MOOC is mainly based on students' self-study, and online learners who cross regions, schools, disciplines, and majors can conduct online learning and communication through online communities. To help learners improve the quality of learning, the platform will recommend the learning sequence and learning methods of courses to learners. After passing the micro-major assessment, they will obtain employment recommendations of platforms. This way of learning is relatively free, which provides new vocational training and development paths for the majority of students and job seekers. However, in the platform, the students lack learning supervision and guidance, so the learning effect is relatively poor. And the practice is mainly based on the simulation projects of enterprises by the students on their own, therefore the internship training courses are hard to effectively implement. Besides, the authority of the corporate certification has always been difficult to be widely approbated.

A few universities in China have also begun to cooperate with MOOC platforms to set up profitable micro-majors for society. For example, Tsinghua University relies on Xuetang Online and Netease Cloud Classroom to set up micro-majors of computer foundation, innovation and entrepreneurship, and business, etc., and Peking University relies on the Wisdom Tree to set up micro-majors of international organization and global governance, etc. Such micro-majors are promoted by top domestic universities with excellent curriculum, so their micro-major certificates are better approbated than those certified by MOOC platforms. But after all, micro-major learning based on MOOC is different from professional learning at universities. Offline guidance and curriculum learning effects are relatively weak, and internship training is also hard to accomplish. Since Chinese colleges and universities are based on public welfare and have relatively insufficient marketing capabilities, the promotion of profitable micro-majors is poor. In recent years, many Chinese colleges and universities are inspired by the rapid and flexible running model of for-profit micro-majors and have begun to set up non-profit micro-majors to meet the changing talent demand.

\section{The New Development of Micro-majors in Chinese Universities}

With the rapid development of science and technology, there is a growing shortage of talents in emerging fields such as smart manufacturing, digital economy, and life and health. The sub-industry within these fields also changed a lot. However, the cultivation of talents in these fields lags in both major construction and curriculum construction. Therefore, it is difficult for universities to cultivate a large number of suitable talents relying on traditional disciplines. These emerging fields also lack MOOC courses, so it is difficult for the micro-majors of MOOC platforms to follow up in time. It is one of the main performance goals to cultivate scarce talents to promote social and economic development for Chinese universities. Therefore, Chinese universities began to develop non-profit micro-majors on their own to meet the ever-changing but large-volume talent demand. In 2014, Zhejiang Gongshang University took the lead in setting up a micro-major in entrepreneurship management. Then, Zhejiang University of Finance and Economics set up micro-majors such as entrepreneurial management and artificial intelligence. East China University of Science and Technology set up 14 micro-majors such as intelligent biological manufacturing

ISSN: 0010-8189 
and international business management. Shandong University set up 17 micro-majors including multiple intelligence etc. Jiangsu University set up 13 micro-majors including artificial intelligence and robotics, big data technology and management, etc. So far, at least more than 40 Chinese universities have set up hundreds of micro-majors. The micro-major talent training model has gradually become a useful supplement to the traditional talent training of universities. It has even been written into the talent training plan and officially become an important part of university education. These micro-majors are mainly for students on campus and are almost non-profit, so they are well promoted.

\subsection{An Important Means to Make up for the Lagging of Majors Setting at Universities}

In recent years, a large number of new professional fields have emerged, but the majors setting of the Ministry of Education has been slow to update, and it is often difficult for universities to apply for emerging majors outside the catalog. The majors setting of colleges and universities also needs to be relatively stable, so it is impossible to adapt to the rapid changes in the emerging professional fields. The contradiction between the talent training of universities and the demand for social employment is becoming serious. Micro-majors can be customized for emerging professional fields, which bring higher autonomy to colleges and universities. Therefore, many colleges and universities introduce micro-majors as a supplementary plan to compensate for the slow update of majors setting. In recent years, micro-majors of intelligent biological manufacturing, multiple intelligence, artificial intelligence and robotics, big data technology and management, entrepreneurial management, cross-border e-commerce, international business management, pathology technology, virtual instrument technology applications, data analysis, artificial intelligence, front/Back-end development, product/operation, etc. developed rapidly [6-11].

\subsection{An Important Supplement to Increase the Supply of Talents in Emerging Industries}

It often takes more than two years for colleges and universities to prepare for a major, apply for a major, and then recruit students. Some majors outside the catalog may even take longer. And it often takes three to six years from the formal enrollment to the graduation of college students. It is difficult to meet the market employment needs in time by applying for new majors with the long training cycle [7,12-14]. And there are certain boundaries between traditional majors, resulting in a limited number of talents for each major. Micro-majors require a relatively lower theoretical foundation and generally recruit students for all the students in the college with a wide training range. As a fast, flexible and low-cost talent training method, micro-majors are also suitable for universities to conduct large-scale talent training for emerging industries. Facing the large and changing demand for talents in emerging industries, colleges and universities are increasingly setting up micro-majors to rapidly realize the connection between college talent training and social job demands [15-16].

\subsection{The Curriculum System Simplifies Theoretical Teaching and Emphasizes Applied Practice}

As an important means for the training of applied talents, micro-majors are targeted at specific positions or entrepreneurial fields. The curriculum is oriented by career or job skills [8,17-20]. Most of the micro-majors are based on the cross integration of existing disciplines and majors at universities. The basic theory courses have been set up in various related majors. Some students already have a certain theoretical foundation. And students who have no foundation can also take the basic courses of the first-related major as needed. Besides, the application-oriented micro-major makes the professional theoretical foundation not strictly required. In this context, most micro-major courses simplify theoretical teaching and enrich practical teaching to reflect the training of applied talents [11]. Some micro-majors directly take the specific vocational certificate as one of the training goals [8-9, 20].

\subsection{Alleviate the Shortage of Education and Teachers in Emerging Vocational Fields}


Colleges and universities for talent training in emerging professional fields often face a serious shortage of their teachers, the micro-major model can better alleviate this difficulty [12,21]. First, the small and sophisticated characteristics of micro-major determine that the total demand for teachers is not large. Secondly, micro-major teaching methods can be flexible and diverse, and teaching online or a combination of online and offline will save teachers' resources [21]. Third, the application-oriented characteristics of micro-majors determine that more school-enterprise cooperation can be introduced to build a faculty team with enterprises $[12,16]$.

\subsection{Online and Offline Teaching Methods are Generally Adopted}

Although micro-majors built based on MOOC can solve the problem of insufficient teachers at universities to a certain extent, and share high-quality online courses of top universities, the practical teaching process is difficult to carry out effectively [13]. According to the survey, $90 \%$ of students are willing to participate in other majors in the short-term, but the learning effect of online teaching is poor [17]. To adapt to the actual situation of students, universities and colleges no longer rely on MOOC platforms to set up micro-majors, but instead develop courses by themselves [19], and implement online and offline teaching methods [6,10-11,13,22]. Since the micro-majors of colleges and universities focus on cultivating their students, some micro-majors at universities also develop offline courses [7].

\subsection{Micro-major Construction Generally Introduces School-enterprise Cooperation Mode}

Micro-majors are mostly career-oriented or post-oriented and the curriculum system highlights practical applications, so the integration of production and education is an inevitable choice [15]. For the cultivation of micro-major talents in emerging industries, the number of teachers at universities is insufficient, and the teachers' practical application ability is weak. Therefore, there are difficulties in developing applied talent training in micro-majors. In this context, universities have generally introduced a school-enterprise cooperation model for the development of micro-major teaching, that relies on both universities and enterprises, to jointly build a teaching team, develop training programs, develop course materials, and build internship training bases [7, 10, 12, 14]. Even companies put forward employment needs, and universities set up order classes based on micro-majors [22].

\subsection{Better Carry out Social Training through Micro-majors}

Social service is one of the basic functions of colleges and universities, and social training is the main content of universities serving the society. At present, Chinese colleges and universities are developing more and more social training for emerging industries, and the development of micro-majors provides a curriculum foundation for colleges and universities to better carry out social training [23]. The micro-majors at universities are based on MOOC or online and offline teaching mode, which also provides conditions for expanding social training [24-26]. Chinese universities have expanded social training activities based on micro-majors.

\section{Countermeasures for Improving the Level of Micro-Major Education in Chinese Universities}

\subsection{Taking into account the Actual Effect of Enrollment Promotion and Practical Teaching}

To expand the scope of the benefits of micro-major students and increase the supply of talents in emerging industries, colleges and universities need to develop MOOC or online and offline courses as much as possible, so that students of different majors could participate in the study. However, as an important way of cultivating applied talents, practical teaching of micro-major is important, which requires a certain number of teachers to carry out offline guidance. Therefore, expanding the scope of the benefits of micro-major is in contradiction with the limitation of teachers. Colleges and universities should rely on the Internet to carry out theoretical courses teaching to save 
teachers resources, but for practical courses, they need to be equipped with the necessary teachers. Meanwhile, colleges and universities should also fully integrate production and education when constructing micro-majors and use corporate teachers and production conditions to carry out student internship training.

\subsection{Build High-quality Application-oriented Teachers}

The faculty establishment of application-oriented teachers is the key for micro-majors construction at universities. It requires: (1) set up a micro-major teaching team. It can make full use of the existing professional teachers to form a micro-major teaching team or teaching and research section through interdisciplinary majors. (2) Build a team of sufficient self-owned dual-qualified and dual-capable teachers. The micro-major faculty should be mainly self-owned teachers, otherwise, it will be difficult in teaching and student management. Appropriate incentive measures can be used to promote the transformation of some teachers into micro-major dual-qualified and dual-capable teachers. On this basis, appropriately applied teachers will be introduced. (3) Make full use of the auxiliary role of industrial teachers. Colleges and universities need to make good use of the school-enterprise collaborative education mechanism to encourage industrial elites to enter campuses and increase applied part-time teachers.

\subsection{Take into Account the Relationship between Micro-majors and Existing Majors}

The establishment of micro-majors at universities is intended to complement existing higher education. First, it needs to be properly misplaced with the existing education model of universities. Micro-majors are not required for a high theoretical basis, so they need to be different from the existing majors in the universities, from the second major or minor majors, and also from the professional modules. Small and sophisticated micro-majors cannot be used to replace normal professional education. Second, it is necessary to seek reasonable coexistence with existing education models. The small and sophisticated characteristics of micro-majors will encourage a large number of students to take courses, which may distract students and have a certain impact on their original majors. Colleges and universities could promote the mutual recognition of micro-major credits and major credits within a certain range, including direct mutual recognition of credits of two similar majors, credits of micro-major basic courses as public elective credits, and micro-major practice credits as majors credits for the practice process (except for special internship training requirements). After completing the studies, students will receive both the original major certificate and the micro-major certificate. Third, develop a model of major education plus micro-major education, to cultivate students' compound abilities through the complementation of the two education. For example, the development of big data micro-majors will better develop big data plus engineering, big data plus economics management, big data plus literature, and other talent training models; the development of cross-border e-commerce micro-majors will better develop cross-border e-commerce plus engineering, Cross-border e-commerce plus language, cross-border e-commerce plus agriculture and other talent training models.

\subsection{Micro-majors Need to Further Highlight Cross-integration}

In recent years, with rapid development and upgrade of technology and industry, new industries and professional fields continue to emerge and change. Most of the professional knowledge required by these emerging industries is the intersection of existing disciplines. Therefore, colleges and universities could rely on their teaching foundation, through the cross integration of disciplines and specialties, and integrate advantageous resources to develop micro-majors, to meet the needs of professional talents that are large in society and cannot be met by the existing colleges and universities. It is foreseeable that for a long time in the future, micro-majors will still be a useful supplementary of talent training for Chinese universities.

\section{Acknowledgements}

ISSN: 0010-8189

(C) CONVERTER 2020 
This research is supported by Zhejiang Educational Science Planning Project (Grant No.2019SCG023).

\section{References}

[1] S. Taneja, A. Goel, "MOOC providers and their strategies," International Journal of Computer Science and Mobile Computing, vol. 3, no. 5, pp. 222-228, 2014.

[2] B. Dasarathy, K. Sullivan, D.C. Schmidt, D.H. Fisher, A. Porter, "The past, present, and future of MOOCs and their relevance to software engineering," Proceedings of the on Future of Software Engineering, vol. 5, pp. 212-224, 2014.

[3] Q. Wang, T. Zhang, "Review of MOOC development in the United States in 2014," e-Education Research, vol. 4, pp. 35-43, 2015.

[4] Y. Wang, "Analysis of MOOC micro-majors and its enlightenment to the construction of MOOCs in China," Distance Education in China, vol. 12, pp. 23-30+79-80, 2018.

[5] H.L. Fan, Y. Peng, "Overview of the Chinese MOOC learning process in NetEase Cloud Classroom," The Chinese Journal of ICT in Education, vol. 23, pp. 32-34, 2014.

[6] X. Jiang, X.J. Li, F. Xu, Q.Q. Wen, "School-wide entrepreneurship education system design based on SPOC-practice of entrepreneurship management micro major of Zhejiang Business University," Talent training and teaching reform: a collection of papers on teaching reform of Zhejiang Gongshang University, vol. 00, pp. 18-24, 2014.

[7] G.C. Jin, H.D. Wen, Y.F. Huang, "Practice and exploration of cross-border e-commerce micro major construction: taking Qianjiang College of Hangzhou Normal University as an example," E-Business Journal, vol. 8, pp. 91-92, 2018.

[8] Y.L. Jin, Z.F. Yang, Y.F. Li, Z.S. Dai, "Discussion on the importance of intelligent pathology technology micro-major in improving clinical pathological diagnosis,” Education Teaching Forum, vol. 48, pp. 147-149, 2020.

[9] B. Zhou, J.H. Zhao, Y.L. Song, "Research and practice of the training program for the application of virtual instrument technology," Modern Vocational Education, vol. 13, pp. 116-117, 2019.

[10] X.Y. Xiang, Z.C. Li, "Exploring the new model of information discipline talent cultivation in local undergraduate colleges: the enlightenment of micro-major model," Computer Knowledge and Technology, vol. 15, no. 18, pp. 163-164+176, 2019.

[11] R. Wang, "Research on the construction of micro-majors in applied undergraduate colleges under the background of new economic construction in the Guangdong-Hong Kong-Macao Greater Bay area," China Journal of Multimedia \& Network Teaching, vol. 4, pp. 115-116, 2020.

[12] C.X. Yang, "Research on the construction of cross-border e-commerce micro-majors in vocational colleges," China Management Informationization, vol. 22, no. 20, pp. 217-218, 2019.

[13] X.M. Wang, W.D. Yang, Q. Wang, Y. Yang, "Curriculum system construction of 'rail traffic signal and control' micro-major,” Education Teaching Forum, vol. 5, pp. 35-37, 2019.

[14] Z.P. Zhang, X.X. Lu, "Study on the construction of big data micro-major," Computer Era, vol. 8, pp. 68-70, 2019.

[15] X.H. Cai, "Research on constructing 'bank customer management' micro-major in colleges," Modern Business Trade Industry, vol. 41, no. 8, pp. 174-175, 2020.

[16] P.Q. Zhao, J.J. Zhang, W.Y. Liu, "Exploration of the micro-major model of applied undergraduate colleges: taking automobile service engineering as an example," Science \& Technology Vision, vol. 21, pp. 58-60, 2020.

[17] Y.Q.Yi, "Exploration and practice of innovative 'small and micro-majors' in higher vocational colleges: taking Dongguan Vocational and Technical College as an example,” Journal of Wuhan Engineering Institute, vol. 30, no. 2, pp. 86-90, 2018.

[18] P. Li, Y. Gu, "Research on the construction of micro-majors based on the studio platform in the deaf 
school: taking handmade jewelry design as an example," Modern Vocational Education, vol. 3, pp. 160-161, 2019.

[19] Y.M. Ge, "Exploration and practice of hierarchical micro-major talents cultivation for computer Majors in higher vocational education," China Information Technology Education, vol. 6, pp. 84-86, 2019.

[20] X.J. Du, Y, Li, L. Liu, "Exploration of the 'micro-major' talent training model of securities investment: taking Harbin Institute of Finance as an example," Science \& Technology Vision, vol. 16, pp. 74-75, 2020.

[21] W. Zhu, K. Zheng, "A Probe into the construction of small and micro professional groups in local colleges and universities in the era of large-scale network courses," Education Teaching Forum, vol. 38, pp. 64-65, 2016.

[22] Q.M. Jiang, L.J. Sun, L. Wang, "Exploration and research on the talent cultivation model of 'micro-majors' in higher vocational colleges," Education Teaching Forum, vol. 42, pp. 241-243, 2018.

[23] F. Yu, D. Xiang, "General situation of micro-major development and its application in electric propulsion ship electromechanical job training," Education Teaching Forum, vol. 52, pp. 214-215, 2018.

[24] S.T. Chen, "Exploration on the construction of the micro-major of armored equipment hydraulic system repair based on MOOC," Science \& Technology Information, vol. 14, no. 32, pp. 169+171, 2016.

[25] Y. Li, K.Y. Fan, Y. Guo, B. Liu, "On the construction of micro-major in military vocational education," Hospital Administration Journal of Chinese People's Liberation Army, vol. 24, no. 7, pp. 675-677, 2017.

[26] F.J. Qi, “Analysis of military vocational education micro-majors,” Continuing Education, vol. 31, no. 5, pp. 13-14, 2017. 